\title{
Prevalence of scarred and dysfunctional myocardium in patients with heart failure of ischaemic origin: A cardiovascular magnetic resonance study
}

Christos V Bourantas ${ }^{*}{ }^{\dagger}$, Nikolay P Nikitin ${ }^{\dagger}$, Huan P Loh, Elena I Lukaschuk, Nassar Sherwi, Ramesh de Silva, Ann C Tweddel, Mohamed F Alamgir, Kenneth Wong, Sanjay Gupta, Andrew L Clark and John GF Cleland

\begin{abstract}
Background: Cardiovascular magnetic resonance (CMR) with late gadolinium enhancement (LGE) can provide unique data on the transmural extent of scar/viability. We assessed the prevalence of dysfunctional myocardium, including partial thickness scar, which could contribute to left ventricular contractile dysfunction in patients with heart failure and ischaemic heart disease who denied angina symptoms.

Methods: We invited patients with ischaemic heart disease and a left ventricular ejection fraction $<50 \%$ by echocardiography to have LGE CMR. Myocardial contractility and transmural extent of scar were assessed using a 17-segment model.

Results: The median age of the 193 patients enrolled was 70 (interquartile range: 63-76) years and 167 (87\%) were men. Of 3281 myocardial segments assessed, 1759 (54\%) were dysfunctional, of which 581 (33\%) showed no scar, $623(35 \%)$ had scar affecting $\leq 50 \%$ of wall thickness and 555 (32\%) had scar affecting > 50\% of wall thickness. Of 1522 segments with normal contractile function, only 98 (6\%) had evidence of scar on CMR. Overall, 182 (94\%) patients had $\geq 1$ and 107 (55\%) patients had $\geq 5$ segments with contractile dysfunction that had no scar or $\leq 50 \%$ transmural scar suggesting viability.

Conclusions: In this cohort of patients with left ventricular systolic dysfunction and ischaemic heart disease, about half of all segments had contractile dysfunction but only one third of these had $>50 \%$ of the wall thickness affected by scar, suggesting that most dysfunctional segments could improve in response to an appropriate intervention.
\end{abstract}

Keywords: Heart failure, Myocardial infarction, Hibernation, Cardiovascular magnetic resonance imaging, Late gadolinium enhancement

\section{Background}

Ischaemic heart disease (IHD) is a common cause of left ventricular (LV) systolic dysfunction leading to chronic heart failure (CHF) [1]. Patients with lower LV ejection fraction (EF) and more extensive coronary artery disease have a worse prognosis [2]. LV systolic dysfunction in patients with IHD may be due to either myocardial

\footnotetext{
* Correspondence: cbourantas@gmail.com

† Contributed equally

Department of Cardiology, Academic Unit, University of Hull, Postgraduate Medical Institute, Kingston-upon-Hull, UK
}

necrosis leading to scar, or to impaired myocardial contractility despite myocardial viability (hibernation or stunning) [3]. Viable but dysfunctional myocardium can potentially recover if the ratio of myocardial oxygen supply to demand can be improved either by coronary revascularisation or with anti-ischaemic treatment, although recovery of function may take months or even years [4-7]. Many hearts are likely to have systolic dysfunction related to a complex substrate including variable quantities of myocardium affected by full or partial 
thickness scar, stunning, hibernation, and reversible ischemia.

The proportion of patients who have a substantial volume of myocardium that is dysfunctional but viable is uncertain [8]. The inconsistencies in available data may be related to limitations of the imaging methods conventionally used to detect myocardial viability (myocardial perfusion scintigraphy, positron emission tomography and stress echocardiography) or the populations studied. Cardiovascular magnetic resonance (CMR) with late gadolinium enhancement (LGE) is a high-resolution imaging method that can estimate scar volume and transmurality and provide information regarding myocardial viability. The method is based on the accumulation of paramagnetic contrast (gadolinium) in necrotic (acute infarction) or scar tissue. Myocardial injury without necrosis or scarring does not lead to LGE despite the presence of myocardial hibernation/stunning [9-11]. Given the high spatial resolution of CMR, it is possible to measure not only the number of myocardial segments affected but also the transmural extent of scar, a capability unmatched by other imaging techniques. Scars affecting $\leq 50 \%$ of the thickness of the myocardial wall appear to predict functional improvement following revascularisation or medical therapy $[11,12]$.

Revascularisation might lead to improvement in $\mathrm{LV}$ systolic function and improve the clinical state of patients with CHF. However, the potential for revascularisation is dependent upon the extent of reversible ischaemia as opposed to scar in the areas to be revascularised. In addition, the extent and distribution of transmural scar may also affect the response to cardiac resynchronisation therapy (CRT) $[13,14]$. We therefore designed the present study to investigate the prevalence and distribution of scarred myocardium (and assess the relationship between contractile dysfunction and the extent of myocardial scar) in an epidemiologically-representative group of patients with CHF and IHD, who did not complain of symptoms of angina and in whom revascularisation as a treatment option was not excluded by severe co-morbidities or frailty.

\section{Methods}

\section{Study subjects}

We prospectively enrolled patients with stable clinical signs and symptoms of CHF (New York Heart Association (NYHA) functional class I to III) due to LV ventricular systolic dysfunction and IHD attending a community-based heart failure clinic serving a population of just over 0.5 million. The diagnosis of heart failure was based on symptoms and signs assessed by a cardiologist. Patients with a baseline echocardiogram showing a LVEF $<50 \%$ were considered to have systolic dysfunction. The diagnosis of IHD was confirmed by a history of myocardial infarction, coronary revascularisation or $>50 \%$ of luminal diameter coronary stenoses on angiography [15].

Exclusion criteria were significant primary valvular or congenital heart disease, a myocardial infarction or revascularisation during the 12 months prior to recruitment, and conventional contraindications to CMR (metal in the eye or in the brain, pacemakers or defibrillators, and claustrophobia). Patients who reported anginal symptoms were also excluded from the study since these patients would be expected to have substantial amounts of viable myocardium subtended by diseased coronary arteries. Patients with severe co-morbidities or who were considered too frail for revascularisation were also excluded.

Patients were first treated with appropriate pharmacological treatment including diuretics, renin-angiotensinaldosterone system (RAAS) inhibitors, $\beta$-blockers and aldosterone antagonists unless contra-indicated or not tolerated and were seen regularly in a heart failure clinic to ensure continued optimisation of treatment and were then referred for CMR. Typically there was a delay (mean \pm standard deviation: $4 \pm 5.5$ months) between initial assessment and CMR during which ventricular function may have improved with therapy. Written informed consent was obtained in all study patients. The study complies with the Declaration of Helsinki and was approved by the local research ethics committee.

\section{Cardiac magnetic resonance imaging}

Patients underwent CMR on a 1.5 Tesla scanner (Signa $\mathrm{CV} / \mathrm{i}$, GE Medical Systems) using ECG-triggered breathhold gradient-echo in steady-state acquisition (FIESTA) imaging. After initial localizing scans, cine LV horizontal long-axis, vertical long-axis and contiguous short-axis images covering the LV from apex to base (slice thickness $10 \mathrm{~mm}$ ) were obtained. The multi-slice short-axis cine data sets were analyzed by an expert observer whose reliability and reproducibility has already been tested (Table 1) [16]. This observer manually traced the endocardial and epicardial borders in the end-diastolic and end-systolic frames, in each one of the contiguous short-axis slices using specialized software (MEDIS, Leiden, NL). These borders were then used to calculate LV end-diastolic volume (EDV), end-systolic volume (ESV), $\mathrm{EF}$ and myocardial mass (MM). The indices of EDV, ESV and MM were obtained by correcting for body surface area. Wall thickening was assessed blind to the LGE results by an expert observer using a 17-segment model as recommended by the American Heart Association [17]. The segments were classified as normal or dysfunctional (mildly hypokinetic, severely hypokinetic, akinetic or dyskinetic) on the basis of visual assessment. 
Table 1 Intra- and interobserver variability for the left ventricular indices.

\begin{tabular}{lccc}
\hline & CMR measurements & $\begin{array}{c}\text { Intra-observer variability } \\
(\mathbf{n}=\mathbf{3 0})\end{array}$ & $\begin{array}{c}\text { Inter-observer variability } \\
(\mathbf{n}=\mathbf{3 0})\end{array}$ \\
\hline LVEF $(\%)$ & $35.6 \pm 9.1$ & $0.1 \pm 2.7$ & $0.0 \pm 2.1$ \\
LVEDV index $\left(\mathrm{ml} / \mathrm{m}^{2}\right)$ & $121 \pm 41$ & $1.2 \pm 3.7$ & $-1.2 \pm 1.3$ \\
LVESV index $\left(\mathrm{ml} / \mathrm{m}^{2}\right)$ & $83 \pm 38$ & $0.6 \pm 2.8$ & $-1.0 \pm 3.2$ \\
LVMM index $\left(\mathrm{g} / \mathrm{m}^{2}\right)$ & $83 \pm 22$ & $1.4 \pm 2.9$ & $-0.3 \pm 3.3$ \\
\hline
\end{tabular}

Results are presented as mean \pm standard deviation

LV, left ventricle; EF, ejection fraction; EDV, end-diastolic volume; ESV, end-systolic volume index; MM, myocardial mass.

The reproducibility and reliability of the observer who visually evaluated the presence of wall thickening abnormalities was examined in 30 randomly selected CMR scans. The observer reviewed the data twice within 2 months blind to the results of the first scan. A second observer reviewed the same scans once. Intraand interobserver agreement was high with Cohen's $k$ being close to unity $(k=0.90, p>0.001$ and $k=0.88, p$ $>0.001$, respectively).

\section{CMR with LGE}

A commercially available gadolinium-based contrast agent, gadodiamide (Omniscan, GE Healthcare, Amersham, UK), was injected intravenously at a dose of $0.1 \mathrm{mmol} / \mathrm{kg}$ of body weight, and 10-15 min after the injection CMR was performed using a segmented inversion-recovery fast gradient echo sequence that has been described in detail previously [18]. LGE images were acquired in multiple shortaxis views identical to those obtained for cine CMR. The planimetric analysis of LGE images was performed automatically using the MASS-PLUS module of MRI-MASS software (MEDIS, Leiden, NL). The software provides a semiautomatic threshold tool that allows the identification of pixels showing signal intensity higher than a pre-defined threshold ( $>2$ standard deviations above normal myocardium). The same 17-segment model was used with the area of LGE enclosed by the epicardial and endocardial contours measured in 6 basal, 6 mid-cavity and 4 apical segments and the extent of LGE was defined as a percentage of LGE area relative to total segment area [17]. Segments were then graded semi-quantitatively using the following scale: no LGE, $1 \%$ to $25 \%, 26 \%$ to $50 \%, 51 \%$ to $75 \%$, and $76 \%$ to $100 \%$ of wall thickness. Visual estimation of LGE extent in LV horizontal and vertical long-axis views was used for the assessment of the $17^{\text {th }}$ segment (apex).

Potentially viable but dysfunctional myocardial segments were defined as those with impaired thickening but with $\leq 50 \%$ LGE [11]. A patient was classified as having "substantial" myocardial viability if 5 or more such segments were present.

\section{Statistical analysis}

Results are presented as median and interquartile range (IQR) for continuous variables or as numbers (percentages) for categorical variables. Comparisons between sub-groups were made using the Mann-Whitney $U$ test for continuous variables and the chi-square test for categorical variables. Linear regression analysis and the Pearson correlation coefficient was apply to examine the association between LVEF and the number of dysfunctional segments. A $P$ value $<0.05$ was considered significant.

\section{Results}

\section{Study subjects}

Clinical characteristics of the study population are shown in Table 2. Of 193 patients, only 129 (67\%) had suffered a clinically documented myocardial infarction and 71 (37\%) had undergone coronary revascularisation prior to initial assessment. No patients had undergone revascularisation between initial assessment and CMR scanning. Co-morbidities, such as arterial hypertension (resting systolic blood pressure $>140 \mathrm{mmHg}$ or diastolic $>90 \mathrm{mmHg}$ or patients already under medical treatment for elevated blood pressure) and diabetes mellitus, were common. Most patients were receiving $\beta$-blockers and RAAS inhibitors and had received this treatment for > 12 months prior to CMR.

On CMR, 186 patients had at least one dysfunctional segment while seven patients had normal systolic function. LGE was observed in 169 (88\%) patients. Substantial myocardial viability, that is $\geq 5$ dysfunctional segments with $\leq 50 \%$ LGE, was found in 107 (55\%) patients of whom 49 (25\%) had $\geq 5$ dysfunctional segments with no scar and 25 (13\%) patients also had $\geq 5$ dysfunctional segments with > 50\% LGE. 64 (33\%) patients had $\geq 5$ dysfunctional segments with $\leq 25 \%$ scar thickness. Dysfunctional segments without LGE were not uncommon, with 104 patients (53\%) having at least one such segment (Figure 1).

Table 2 illustrates differences between the subgroups of patients with and without substantial viability. Patients with substantial viability had to have $\geq 5$ dysfunctional segments, so the proportion of dysfunctional segments was higher in this group than in those without substantial viability $(68 \% v 36 \%)$. Consequently, they had more severe LV systolic dysfunction and dilation and were less likely to tolerate treatment with a RAAS 
Table 2 Characteristics of the patient population $(n=193)$.

\begin{tabular}{|c|c|c|c|c|c|c|c|}
\hline & \multirow{2}{*}{$\begin{array}{c}\text { All patients } \\
(n=193)\end{array}$} & \multicolumn{3}{|c|}{ Absence of substantial viability } & \multicolumn{3}{|c|}{ Substantial Viability } \\
\hline & & $\begin{array}{l}\text { All patients } \\
(\mathrm{n}=86)\end{array}$ & $\begin{array}{c}\text { LVEF } \\
<\text { median } \\
(n=43)\end{array}$ & $\begin{array}{c}\text { LVEF } \\
>\text { median } \\
(\mathrm{n}=43)\end{array}$ & P1 & $(n=107)$ & $P 2$ \\
\hline Age, years & $70(63-75)$ & $69(59-76)$ & $69(61-76)$ & $66(59-76)$ & 0.534 & $70(65-75)$ & 0.283 \\
\hline Male sex & $167(87 \%)$ & 77 (90\%) & $37(86 \%)$ & $40(93 \%)$ & 0.291 & $90(84 \%)$ & 0.273 \\
\hline $\mathrm{BMI}\left(\mathrm{kg} / \mathrm{m}^{2}\right)$ & $28(25-31)$ & $27(25-31)$ & $29(25-32)$ & $26(24-30)$ & 0.111 & $28(25-31)$ & 0.773 \\
\hline Systolic blood pressure mmHg) & $123(111-140)$ & $132(110-148)$ & $117(102-145)$ & $136(123-149)$ & 0.002 & $120(111-134)$ & 0.084 \\
\hline Diastolic blood pressure $(\mathrm{mmHg})$ & $73(65-80)$ & $74(64-84)$ & $72(61-80)$ & $74(66-86)$ & 0.296 & $72(65-80)$ & 0.641 \\
\hline Heart rate (bpm) & $65(59-75)$ & $63(58-70)$ & $64(58-74)$ & $62(57-68)$ & 0.308 & $66(59-76)$ & 0.057 \\
\hline NYHA classification & & & & & 0.022 & & 0.357 \\
\hline NYHA class I & $32(17 \%)$ & $12(14 \%)$ & $3(14 \%)$ & $9(21 \%)$ & & $20(19 \%)$ & \\
\hline NYHA class ॥ & $124(64 \%)$ & $60(70 \%)$ & $29(67 \%)$ & $31(72 \%)$ & & $64(60 \%)$ & \\
\hline NYHA class III & $37(19 \%)$ & $14(16 \%)$ & $11(26 \%)$ & $3(7 \%)$ & & $23(21 \%)$ & \\
\hline Previous infarct & $129(67 \%)$ & $62(72 \%)$ & $34(79 \%)$ & $28(65 \%)$ & 0.149 & $67(63 \%)$ & 0.165 \\
\hline Previous revascularisation & $71(37 \%)$ & $29(34 \%)$ & $15(35 \%)$ & $14(33 \%)$ & 0.820 & $42(40 \%)$ & 0.428 \\
\hline \multicolumn{8}{|l|}{ Co-morbidities: } \\
\hline History of hypertension & $56(29 \%)$ & $24(28 \%)$ & $10(23 \%)$ & $14(33 \%)$ & 0.336 & $32(30 \%)$ & 0.761 \\
\hline Diabetes mellitus & $36(19 \%)$ & $13(15 \%)$ & $5(12 \%)$ & $8(19 \%)$ & 0.366 & $23(22 \%)$ & 0.258 \\
\hline \multicolumn{8}{|l|}{ Medications: } \\
\hline$\beta$-blockers & 167 (87\%) & $82(95 \%)$ & $42(98 \%)$ & 40 (93\%) & 0.306 & $85(79 \%)$ & 0.001 \\
\hline RAAS inhibitors & 175 (91\%) & $83(97 \%)$ & $41(95 \%)$ & $42(98 \%)$ & 0.557 & $92(86 \%)$ & 0.012 \\
\hline Diuretics & $130(67 \%)$ & $55(64 \%)$ & $30(70 \%)$ & $25(58 \%)$ & 0.261 & 75 (70\%) & 0.366 \\
\hline Spironolactone & $53(28 \%)$ & $21(24 \%)$ & $16(37 \%)$ & $5(12 \%)$ & 0.006 & $32(30 \%)$ & 0.396 \\
\hline Digoxin & $18(9 \%)$ & $6(7 \%)$ & $4(9 \%)$ & $2(5 \%)$ & 0.397 & $12(10 \%)$ & 0.314 \\
\hline \multicolumn{8}{|l|}{ CMR measurements } \\
\hline LVEF & $34(27-43)$ & $41(29-51)$ & $29(24-38)$ & $50(45-57)$ & & $31(24-35)$ & $<0.0001$ \\
\hline LVEDV index & 117 (95-150) & $103(84-127)$ & $126(101-155)$ & $91(69-104)$ & $<0.0001$ & $129(111-156)$ & $<0.0001$ \\
\hline LVESV index & $78(55-110)$ & $57(41-83)$ & $82(69-113)$ & $42(32-54)$ & $<0.0001$ & $89(72-117)$ & $<0.0001$ \\
\hline LVMM index & $82(71-101)$ & $80(68-97)$ & $91(73-106)$ & $75(65-84)$ & 0.002 & $85(74-101)$ & 0.120 \\
\hline \multicolumn{8}{|l|}{ Segmental analysis } \\
\hline Segments & 3281 & 1462 & 731 & 731 & & 1819 & \\
\hline Dysfunctional Segments & 1759 (53\%) & $527(36 \%)$ & $154(21 \%)$ & $373(51 \%)$ & $<0.0001$ & $1232(68 \%)$ & \\
\hline Dysfunctional segments without LGE & $581(18 \%)$ & $31(2 \%)$ & $14(2 \%)$ & $17(2 \%)$ & 0.884 & $550(30 \%)$ & \\
\hline Dysfunctional segments with LGE & $1178(36 \%)$ & $496(34 \%)$ & 140 (19\%) & $356(49 \%)$ & $<0.0001$ & $682(37 \%)$ & \\
\hline Dysfunctional segments with > 50\% LGE & $559(17 \%)$ & $313(21 \%)$ & $65(9 \%)$ & $248(34 \%)$ & $<0.0001$ & $246(14 \%)$ & \\
\hline Segments with normal function - no LGE & $1326(40 \%)$ & $849(58 \%)$ & $513(70 \%)$ & $336(46 \%)$ & $<0.0001$ & $477(26 \%)$ & \\
\hline Segments with normal function and LGE & $98(3 \%)$ & $43(3 \%)$ & $32(4 \%)$ & $11(2 \%)$ & 0.283 & $55(3 \%)$ & \\
\hline
\end{tabular}

Data are expressed as median and interquartile range (IQR) or as number and percentage (\%) of patients.

$P_{1}$ value represents the significance of differences between the subgroups of patients with no substantial viability and LVEF $>$ median (41\%) and those with LVEF $<$ median

$P_{2}$ value expresses comparison between the groups with significant viability and no significant viability

LV, left ventricular; EF, ejection fraction; BMI, body mass index; NYHA, New York Heart Association; RAAS, rennin-angiotensin-aldosterone system; EDV, enddiastolic volume; ESV, end-systolic volume; MM, myocardial mass; LGE, late gadolinium enhancement.

inhibitor and a $\beta$-blocker. In other words, patients with more severe LV dysfunction were more likely to have substantial viability (Figure 2). On the other hand the patients without substantial viability appeared to constitute an inhomogeneous group. The subgroup of patients with a LVEF below the median $(<41 \%)$ had a considerable proportion of scarred and dysfunctional myocardium while the group with LVEF $>41 \%$ had few segments with myocardial dysfunction or scar, consistent with recovery of ventricular function in response to medical therapy.

57 patients (29\%) had $\geq 5$ segments with scar thickness $>50 \%$ but 2 out of 5 of them (24 patients) also had $\geq 5$ dysfunctional segments with no or $\leq 50 \%$ partial thickness scars. Compared to the other patients they had lower LVEF (29\% (22\%-34\%) v 37\% (29\%-45\%), $P<$ $0.0001)$ and increased LVEDV index $\left(131 \mathrm{ml} / \mathrm{m}^{2}(112\right.$ $\left.\mathrm{ml} / \mathrm{m}^{2}-173 \mathrm{ml} / \mathrm{m}^{2}\right) v 114 \mathrm{ml} / \mathrm{m}^{2}\left(92 \mathrm{ml} / \mathrm{m}^{2}-145 \mathrm{ml} / \mathrm{m}^{2}\right)$, 


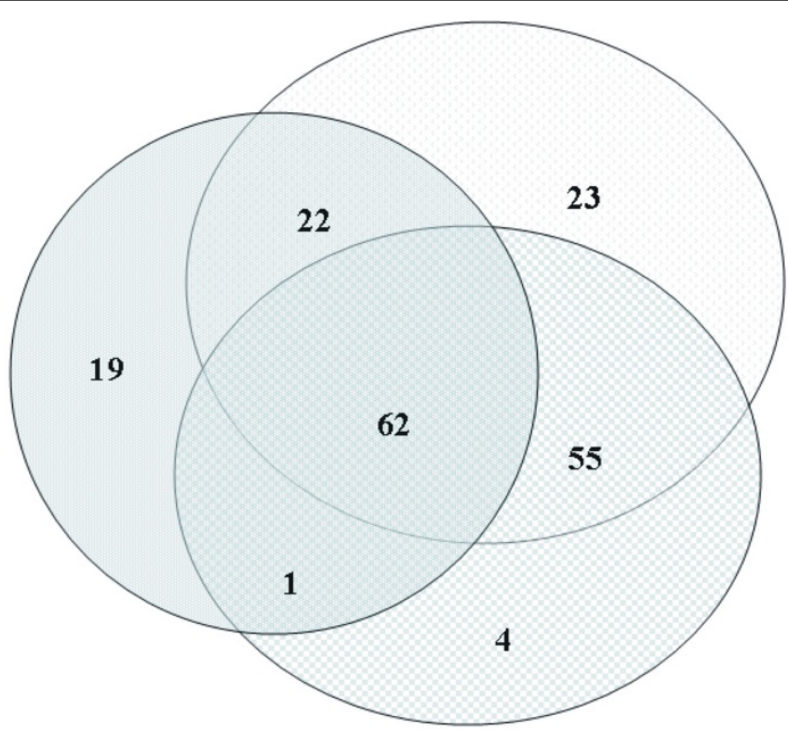

Presence of dysfunctional segments with no scar

Presence of dysfunctional segments with $\leq 50 \%$ scar thickness

Presence of dysfunctional segments with $>50 \%$ scar thickness

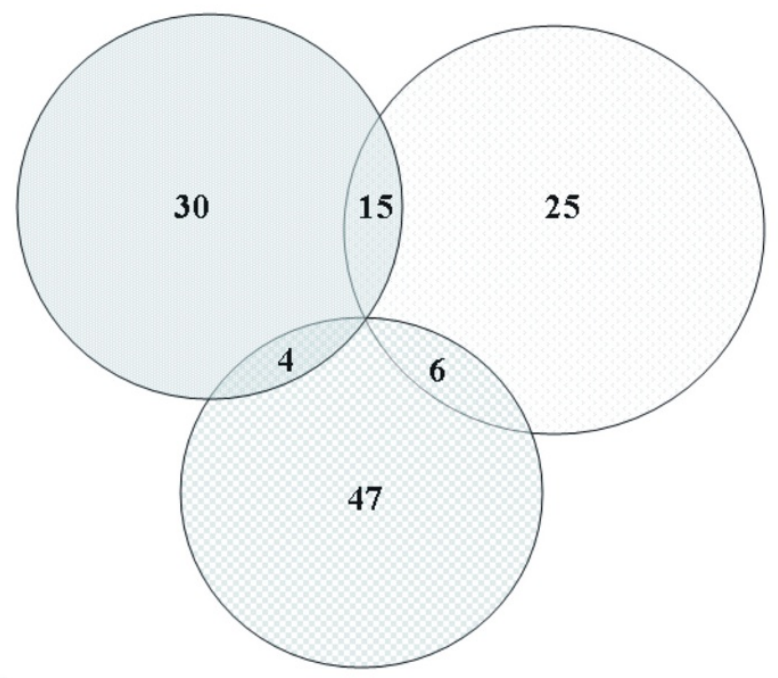

Presence of $\geq 5$ dysfunctional segments with no scar

Presence of $\geq 5$ dysfunctional segments with $\leq 50 \%$ scar thickness

B

Presence of $\geq 5$ dysfunctional segments with $>50 \%$ scar thickness

Figure 1 Two Vein diagrams of which the first shows the presence of dysfunctional segments with $>50 \%$, $\leq 50 \%$ and without late gadolinium enhancement (LGE) (A), and the second the occurrence of $\geq 5$ dysfunctional segments with $>50 \%, \leq 50 \%$ and no $L G E$ (B) in the studied population.

$P=0.001)$ and LVESV index $\left(94 \mathrm{ml} / \mathrm{m}^{2}\left(75 \mathrm{ml} / \mathrm{m}^{2}-126\right.\right.$ $\left.\mathrm{ml} / \mathrm{m}^{2}\right)$ v $\left.72 \mathrm{ml} / \mathrm{m}^{2}\left(51 \mathrm{ml} / \mathrm{m}^{2}-100 \mathrm{ml} / \mathrm{m}^{2}\right), P<0.0001\right)$ but there were no differences in the LVMM index $(82$ $\mathrm{g} / \mathrm{m}^{2}\left(70 \mathrm{~g} / \mathrm{m}^{2}-97 \mathrm{~g} / \mathrm{m}^{2}\right) \vee 82 \mathrm{~g} / \mathrm{m}^{2}\left(74 \mathrm{~g} / \mathrm{m}^{2}-101 \mathrm{~g} / \mathrm{m}^{2}\right)$, $P=0.507)$.
The prevalence of LGE on a per segment basis is shown in Figure 3. Half of the myocardial segments were dysfunctional. Few segments with normal contractile function (6\%) showed LGE (predominantly $\leq 25 \%$ of wall thickness), while two thirds of segments with 

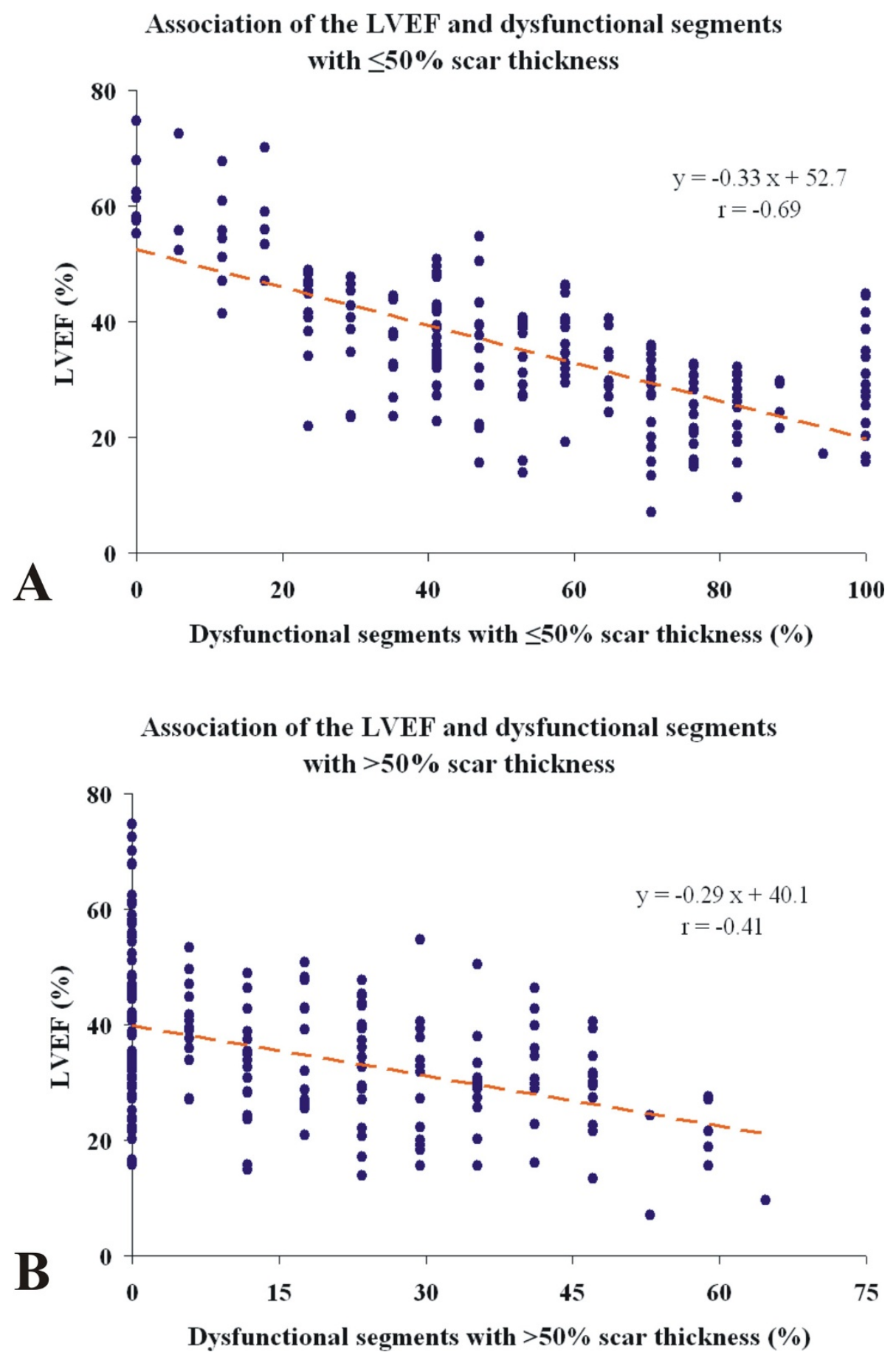

Figure 2 Associations between left ventricular ejection fraction (LVEF) and dysfunctional segments with $\leq 50 \%$ and $>50 \%$ scar thickness.

impaired function demonstrated at least some LGE. Of 1759 segments with contractile dysfunction, 581 had no evidence of myocardial scar, 623 had $\leq 50 \%$, and 555 segments had > 50\% scar thickness.

Figure 4 shows the distribution of scar in the studied population. Myocardial scars were more common in apical and septal regions and less common in the LV free wall (occurrence $54 \% \vee 25 \%, P=0.002$ ). These gradients in distribution were true for partial thickness ( $\leq 50 \%$ scar thickness) and extensive (> 50\%) scars, but more extreme for the latter group $(25 \% \vee 7 \%, P=$ 0.030). 


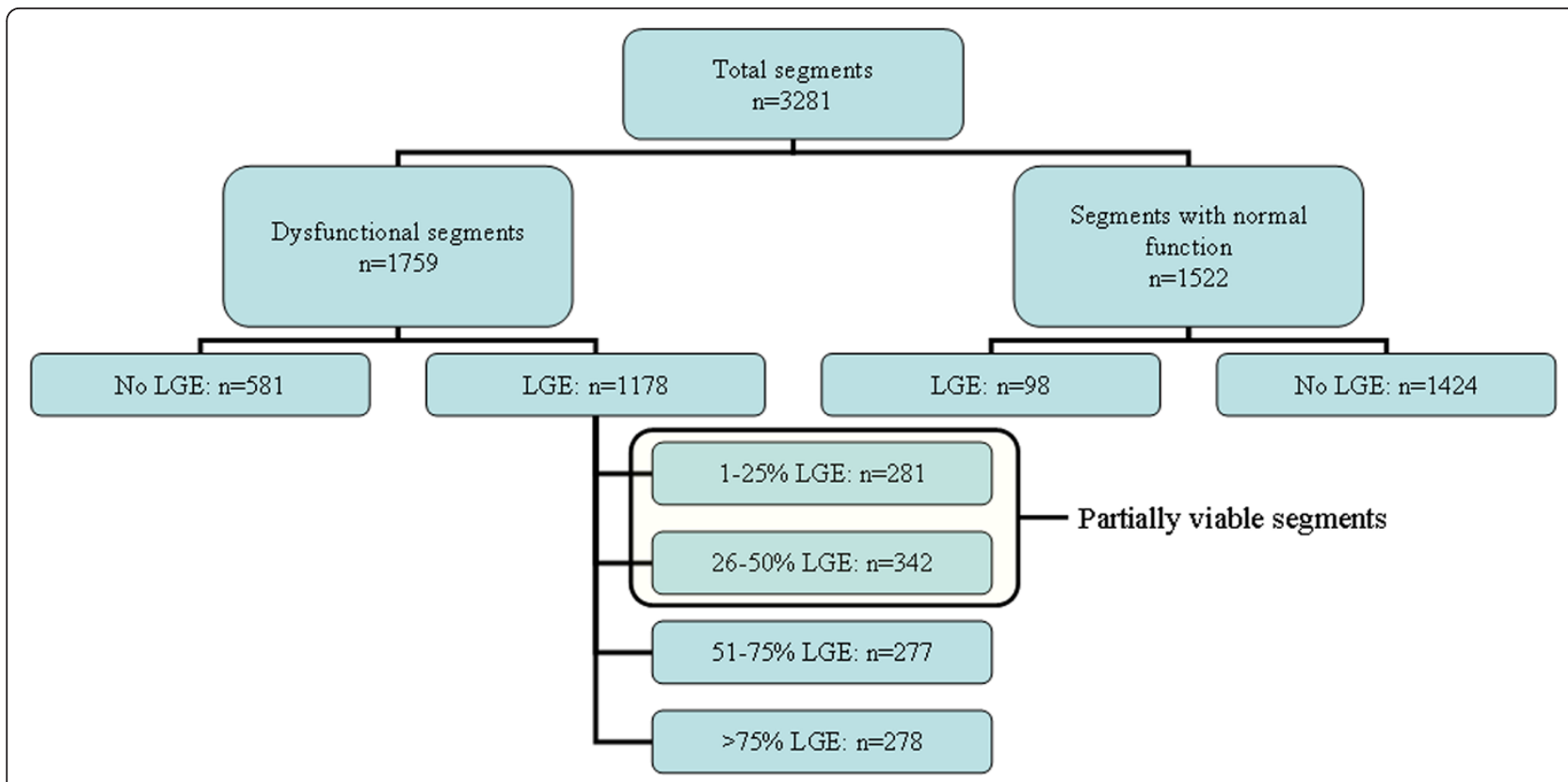

Figure 3 Prevalence of myocardial segments with and without late gadolinium enhancement (LGE).

\section{Discussion}

There is still uncertainty as to the proportion of patients with CHF due to IHD who have a substantial volume of viable but dysfunctional myocardium and who might, therefore have recoverable myocardial function. It is difficult to compare studies because they used different imaging methods, different segmental models and different definitions for the number of affected segments required to declare a substantial problem. In previous echocardiographic or radionuclide studies which specified that a substantial (e.g. 4/16 or 5/19 segments) number of such segments had to be present, the proportion of patients with a substantial amount of viable but dysfunctional myocardium ranged from $27 \%$ to $61 \%$ [7,19-21].

The inability of these techniques to distinguish the relative amounts of scar and viable tissue may limit their use in predicting the recovery of dysfunctional myocardium in response to therapy. Nuclear imaging methods detect viability by assessing perfusion, cell membrane integrity and metabolism but have limited spatial resolution and do not image scar directly [22]. Two small studies have compared the diagnostic accuracy of positron emission tomography and CMR with LGE and one showed that the latter is superior to nuclear imaging in detecting non-viable segments while the other found no difference between the two techniques $[23,24]$. No studies have compared the diagnostic accuracy of stress echocardiography and CMR with LGE but the CMR is likely to be superior in patients with atrial fibrillation and in those with poor acoustic windows [25]. In addition, there is pathological evidence that hibernating tissue can lose its contractile apparatus and therefore its ability to thicken in response to inotropic stimuli [26]. Thus, echocardiography may not be as reliable method as CMR in assessing myocardial viability. In contrast, CMR supplemented by contrast studies permits the accurate and reproducible assessment of contractility and scar with a single imaging technique [10-12].

Our study highlights the complexity of the myocardial substrate in patients with CHF and IHD. Moderate to severe contractile dysfunction was most commonly associated with partial thickness scar, with slightly more than half of the patients having five or more segments affected. Contractile dysfunction in the absence of underlying scar was also commonly observed, a disturbance of myocardial metabolism most likely induced by ischaemia, hibernation or stunning. Finally, extensive (> $50 \%)$ scar was also frequent and affected one third (32\%) of the dysfunctional segments. There is likely to be an added complexity in segments with partial thickness scar, where contractile dysfunction will reflect not only the extent of the scar but also the contractility of the remaining myocardium. Ischaemia, hibernation and stunning of the residual myocardium is likely to be common in these segments.

Some meta-analyses have shown that revascularisation in patients with viable myocardium improves outcome [27]. On the other hand two randomised control trials that have been recently published showed a neutral effect of revascularisation on prognosis. Unfortunately, 


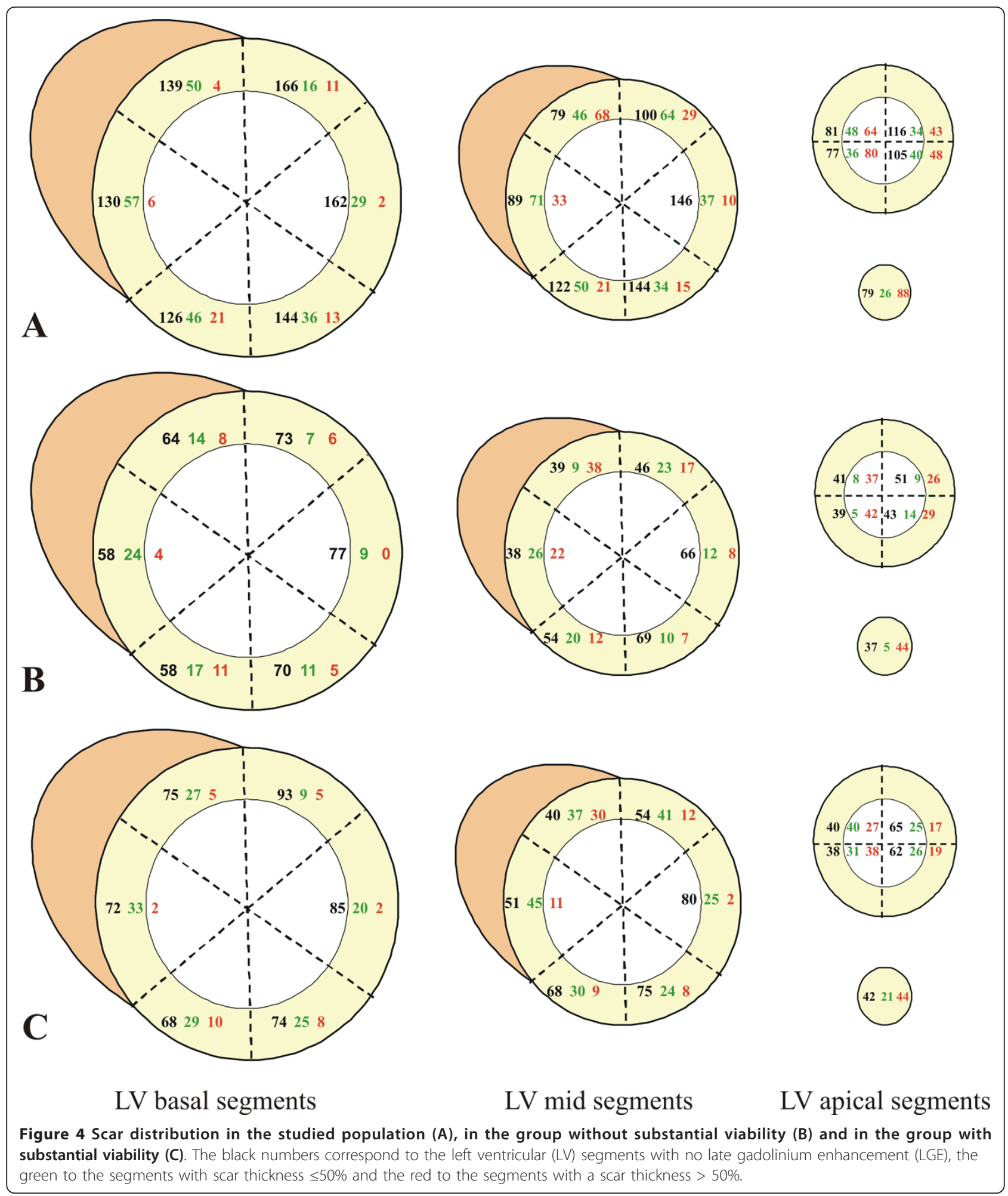

the Heart Failure Revascularisation Trial (HEART) (in which patients with LV systolic dysfunction and a substantial volume of viable myocardium were randomised to medical treatment or revascularisation) was stopped early due to problems with recruitment and funding [28]. Only 138 patients were enrolled. There were no differences in all cause mortality, quality of life or (in a sub-study) systolic function as measured by CMR. 
However, the study was underpowered and thus the final results needed to be further confirmed [29]. The second trial, STICH (Surgical Treatment for Ischemic Heart Failure), showed no effect of revascularisation on death, but perhaps a modest effect on cardiovascular death or hospitalisations [30]. A sub-study of STICH trial examined the prognostic effect of revascularisation in patients with substantial viability [31]. This included 601 patients (487 with substantial viable myocardium) with a LVEF $\leq 35 \%$ who were followed-up for 5 years. The reported results demonstrated that revascularisation did not appear to improve outcomes (total mortality, cardiovascular mortality or the combined end-point total mortality/hospitalisation due to cardiovascular causes). Though this sub-study provides evidence that revascularisation has a neutral impact on hard endpoints it remains unclear whether it should be implemented in patients suffering from CHF with substantial viability to restore myocardial contractility, reduce heart failure symptoms and improve quality of life.

Ultimately, assessing the extent to which LV dysfunction is due to myocardial scar may be more important than trying to assess the potential for functional recovery when assessing a patient for revascularisation. With existing therapies, myocardial scar reflects irreversible damage. Successful revascularisation might not only eliminate myocardial ischaemia and stunning and resuscitate hibernating myocardium but also reduce the risk to viable myocardium, whether or not it is dysfunctional, from further coronary occlusions. The potential of attempted revascularisation to cause irreversible myocardial damage, to which hibernating myocardial may be more prone, should also be considered [32].

Our results may also be important for the selection of patients for CRT. Extensive myocardial scar, perhaps especially when it affects the postero-lateral wall of the $\mathrm{LV}$ predicts a lower chance of recovery of ventricular function with CRT $[13,14]$. This may reduce the functional response to CRT but it is not clear whether it also translates into a lesser impact in terms of prognosis [33]. However, it is reassuring that transmural scar in the postero-lateral wall was relatively uncommon in this population as only $8 \%$ of the patients had scar $>50 \%$ and only $4 \%$ of the patients had $>75 \%$ scar in this region.

\section{Limitations}

There was a delay between the initial echocardiographic assessment of cardiac function and CMR. During that period, treatment with RAAS inhibitors and $\beta$-blockers were initiated or increased, which may have led to recovery of function in viable myocardial segments. Accordingly, this report will underestimate the prevalence of viable but dysfunctional myocardial segments in a treatment naïve population, although it is still a good estimate of the proportion of segments with extensive scar.

Although the evaluation of the contractile function of the myocardial segments was based on wall thickness it is possible that tethering or reciprocal changes caused by neighboring dyssynchronous segments could lead to inaccurate estimations. By convention, a myocardial segment was considered viable if $\leq 50 \%$ of the segment showed LGE. However, a strict definition of "viability" requires that the segment's contractility improves after revascularisation. As our patients are not routinely revascularised in the absence of angina, we cannot be certain that the segments we have labeled "viable" meet this definition. Although available, the end-diastolic wall thickness of the studied segments was not included in our analysis as the conventional cut-off value of $<5.5$ $\mathrm{mm}$ is not accurate in excluding functional recovery after revascularisation [34,35]. A significant limitation of this study is the absence of CMR with low-dose dobutamine stress testing that would allow more reliable identification of segments that would improve their function after revascularisation (especially in cases with intermediate extent of scar tissue) [36].

We used the cut-off of 5 segments to define "substantial" myocardial viability since observational studies show that functional improvement following revascularisation is more likely if a third of LV segments show contractile dysfunction with viability [17]. However, recently Pegg et al. demonstrated that myocardial recovery after revascularisation depends not only on the number of the segments with partial scar thickness but also on the number of the normal segments [6]. Considering that this was a small study (only 33 patients were included) it has been decided to use a cut-off ( $\geq 5$ segments) value already implemented in larger studies, albeit that these used stress echocardiography to define substantial viability $[31,37,38]$. We acknowledge the limitation of extrapolating this methodology to the present CMR based study and recognize the need for further research to test and refine these criteria preferably in the context of large randomised trials of relevant interventions.

\section{Conclusions}

Viable but dysfunctional myocardial segments in patients with CHF due to LV systolic dysfunction and IHD remain common despite contemporary medical therapy and frequently reflect two different pathologies, partial thickness scar and contractile dysfunction, that may have different prognostic and therapeutic implications. The extent of myocardial scar, which currently reflects irreversible damage, may be a useful guide to the likely extent of recovery of ventricular function with pharmacological interventions and revascularisation. 


\section{Acknowledgements}

The study was supported in part by the Project grant No. PG/04/038/16930 from the British Heart Foundation, London, UK. We are grateful to GE Healthcare, Amersham, UK for providing gadodiamide (Omniscan). We wish to thank the team of physicians and nurses in the Academic Unit of Cardiology in Hull and the team of radiologists and radiographers at Castle Hill Hospital, for assistance with conducting the study and Dr Alan S Rigby, MSc, CStat for statistical support.

\section{Authors' contributions}

CVB involved in data analysis and drafting the manuscript; NPN designed the study and involved in drafting the manuscript; HPL RdeS and NS contributed in data collection and interpretation, EIL analyzed the CMR images, ACT, MFA and SG revised the manuscript for important intellectual content while KW interpreted the study findings and ALC and JGFC were the general supervisors of this study. All authors have read and approved the manuscript.

\section{Competing interests}

The authors declare that they have no competing interests.

Received: 26 February 2011 Accepted: 21 September 2011 Published: 21 September 2011

\section{References}

1. Gheorghiade M, Bonow RO: Chronic heart failure in the united states: A manifestation of coronary artery disease. Circulation 1998, 97:282-289.

2. Bart BA, Shaw LK, McCants CB Jr, Fortin DF, Lee KL, Califf RM, O'Connor CM: Clinical determinants of mortality in patients with angiographically diagnosed ischemic or nonischemic cardiomyopathy. J Am Coll Cardiol 1997, 30:1002-1008.

3. Camici $P G$, Wijns W, Borgers $M$, De Silva R, Ferrari R, Knuuti J, Lammertsma AA, Liedtke AJ, Paternostro G, Vatner SF: Pathophysiological mechanisms of chronic reversible left ventricular dysfunction due to coronary artery disease (hibernating myocardium). Circulation 1997, 96:3205-3214.

4. Afridi I, Grayburn PA, Panza JA, Oh JK, Zoghbi WA, Marwick TH: Myocardial viability during dobutamine echocardiography predicts survival in patients with coronary artery disease and severe left ventricular systolic dysfunction. J Am Coll Cardiol 1998, 32:921-926.

5. Rizzello V, Poldermans D, Boersma E, Biagini E, Schinkel AF, Krenning B, Elhendy A, Vourvouri EC, Sozzi FB, Maat A, Crea F, Roelandt JR, Bax JJ: Opposite patterns of left ventricular remodeling after coronary revascularization in patients with ischemic cardiomyopathy: Role of myocardial viability. Circulation 2004, 110:2383-2388.

6. Pegg TJ, Selvanayagam JB, Jennifer J, Francis JM, Karamitsos TD, Dall'Armellina E, Smith KL, Taggart DP, Neubauer S: Prediction of global left ventricular functional recovery in patients with heart failure undergoing surgical revascularisation, based on late gadolinium enhancement cardiovascular magnetic resonance. J Cardiovasc Magn Reson 2010, 12:56.

7. Cleland JG, Pennell DJ, Ray SG, Coats AJ, Macfarlane PW, Murray GD, Mule JD, Vered Z, Lahiri A: Myocardial viability as a determinant of the ejection fraction response to carvedilol in patients with heart failure (christmas trial): Randomised controlled trial. Lancet 2003, 362:14-21.

8. Underwood SR, Bax JJ, vom Dahl J, Henein MY, Knuuti J, van Rossum AC, Schwarz ER, Vanoverschelde JL, van der Wall EE, Wijns W: Imaging techniques for the assessment of myocardial hibernation. Report of a study group of the european society of cardiology. Eur Heart J 2004, 25:815-836.

9. Gerber BL, Garot J, Bluemke DA, Wu KC, Lima JA: Accuracy of contrastenhanced magnetic resonance imaging in predicting improvement of regional myocardial function in patients after acute myocardial infarction. Circulation 2002, 106:1083-1089.

10. Kim RJ, Fieno DS, Parrish TB, Harris K, Chen EL, Simonetti O, Bundy J, Finn JP, Klocke FJ, Judd RM: Relationship of mri delayed contrast enhancement to irreversible injury, infarct age, and contractile function. Circulation 1999, 100:1992-2002.

11. Kim RJ, Wu E, Rafael A, Chen EL, Parker MA, Simonetti O, Klocke FJ, Bonow RO, Judd RM: The use of contrast-enhanced magnetic resonance imaging to identify reversible myocardial dysfunction. N Engl J Med 2000, 343:1445-1453.

12. Selvanayagam JB, Kardos A, Francis JM, Wiesmann F, Petersen SE, Taggart DP, Neubauer S: Value of delayed-enhancement cardiovascular magnetic resonance imaging in predicting myocardial viability after surgical revascularization. Circulation 2004, 110(12):1535-41.

13. Bleeker GB, Kaandorp TA, Lamb HJ, Boersma E, Steendijk P, de Roos A, van der Wall EE, Schalij MJ, Bax JJ: Effect of posterolateral scar tissue on clinical and echocardiographic improvement after cardiac resynchronization therapy. Circulation 2006, 113:969-976.

14. White JA, Yee R, Yuan X, Krahn A, Skanes A, Parker M, Klein G, Drangova M: Delayed enhancement magnetic resonance imaging predicts response to cardiac resynchronization therapy in patients with intraventricular dyssynchrony. J Am Coll Cardiol 2006, 48:1953-1960.

15. Alpert JS, Thygesen K, Antman E, Bassand JP: Myocardial infarction redefined-a consensus document of the joint european society of cardiology/american college of cardiology committee for the redefinition of myocardial infarction. J Am Coll Cardiol 2000, 36:959-969.

16. Bourantas CV, Loh HP, Bragadeesh T, Rigby AS, Lukaschuk El, Garg S, Tweddel AC, Alamgir FM, Nikitin NP, Clark AL, Cleland JGF: Relationship Between Right Ventricular Volumes Measured by Cardiac Magnetic Resonance Imaging and Prognosis in Patients with Chronic Heart Failure. Eur J Heart Fail 2011, 13(1):52-60.

17. Cerqueira MD, Weissman NJ, Dilsizian V, Jacobs AK, Kaul S, Laskey WK, Pennell DJ, Rumberger JA, Ryan T, Verani MS: Standardized myocardial segmentation and nomenclature for tomographic imaging of the heart: A statement for healthcare professionals from the cardiac imaging committee of the council on clinical cardiology of the american heart association. Circulation 2002, 105:539-542.

18. Kim RJ, Shah DJ, Judd RM: How we perform delayed enhancement imaging. J Cardiovasc Magn Reson 2003, 5:505-514.

19. Auerbach MA, Schoder H, Hoh C, Gambhir SS, Yaghoubi S, Sayre JW, Silverman D, Phelps ME, Schelbert HR, Czernin J: Prevalence of myocardial viability as detected by positron emission tomography in patients with ischemic cardiomyopathy. Circulation 1999, 99:2921-2926.

20. Go RT, MacIntyre WJ, Cook SA, Neumann DR, Brunken RC, Saha GB, Underwood DA, Marwick TH, Chen EQ, King JL, Khandekar S: The incidence of scintigraphically viable and nonviable tissue by rubidium- 82 and fluorine-18-fluorodeoxyglucose positron emission tomographic imaging in patients with prior infarction and left ventricular dysfunction. J Nucl Cardiol 1996, 3:96-104.

21. Schinkel AF, Bax JJ, Sozzi FB, Boersma E, Valkema R, Elhendy A, Roelandt JR, Poldermans D: Prevalence of myocardial viability assessed by single photon emission computed tomography in patients with chronic ischaemic left ventricular dysfunction. Heart 2002, 88:125-130.

22. Wagner A, Mahrholdt H, Holly TA, Elliott MD, Regenfus M, Parker M, Klocke FJ, Bonow RO, Kim RJ, Judd RM: Contrast-enhanced mri and routine single photon emission computed tomography (spect) perfusion imaging for detection of subendocardial myocardial infarcts: An imaging study. Lancet 2003, 361:374-379.

23. Kuhl HP, Lipke CS, Krombach GA, Katoh M, Battenberg TF, Nowak B, Heussen N, Buecker A, Schaefer WM: Assessment of reversible myocardial dysfunction in chronic ischaemic heart disease: Comparison of contrastenhanced cardiovascular magnetic resonance and a combined positron emission tomography-single photon emission computed tomography imaging protocol. Eur Heart J 2006, 27:846-853.

24. Wu YW, Tadamura E, Yamamuro M, Kanao S, Marui A, Tanabara K Komeda M, Togashi K: Comparison of contrast-enhanced mri with (18)f$\mathrm{fdg}$ pet/201tl spect in dysfunctional myocardium: Relation to early functional outcome after surgical revascularization in chronic ischemic heart disease. J Nucl Med 2007, 48:1096-1103.

25. Tomlinson DR, Becher H, Selvanayagam JB: Assessment of myocardial viability: Comparison of echocardiography versus cardiac magnetic resonance imaging in the current era. Heart Lung Circ 2008, 17:173-185.

26. Elsasser A, Schlepper M, Klovekorn WP, Cai WJ, Zimmermann R, Muller KD, Strasser R, Kostin S, Gagel C, Munkel B, Schaper W, Schaper J: Hibernating myocardium: An incomplete adaptation to ischemia. Circulation 1997, 96:2920-2931.

27. Allman KC, Shaw LJ, Hachamovitch R, Udelson JE: Myocardial viability testing and impact of revascularization on prognosis in patients with 
coronary artery disease and left ventricular dysfunction: A meta-analysis. J Am Coll Cardiol 2002, 39:1151-1158.

28. Cleland JG, Freemantle N, Ball SG, Bonser RS, Camici P, Chattopadhyay S, Dutka D, Eastaugh J, Hampton J, Large S, Norell MS, Pennell DJ, Pepper J, Sanda S, Senior R, Smith D: The heart failure revascularisation trial (heart): Rationale, design and methodology. Eur J Heart Fail 2003, 5:295-303.

29. Coletta AP, Cleland JG, Cullington D, Clark AL: Clinical trials update from heart rhythm 2008 and heart failure 2008: Athena, urgent, inh study, heart and ck-1827452. Eur J Heart Fail 2008, 10:917-920.

30. Velazquez EJ, Lee KL, Deja MA, Jain A, Sopko G, Marchenko A, Ali IS, Pohost G, Gradinac S, Abraham WT, Yii M, Prabhakaran D, Szwed H, Ferrazzi P, Petrie MC, O'Connor CM, Panchavinnin P, She L, Bonow RO, Rankin GR, Jones RH, Rouleau JL, STICH Investigators: Coronary-artery bypass surgery in patients with left ventricular dysfunction. $N$ Engl J Med 2011, 364(17):1607-16.

31. Bonow RO, Maurer G, Lee KL, Holly TA, Binkley PF, Desvigne-Nickens P, Drozdz J, Farsky PS, Feldman AM, Doenst T, Michler RE, Berman DS, Nicolau JC, Pellikka PA, Wrobel K, Alotti N, Asch FM, Favaloro LE, She L, Velazquez EJ, Jones RH, Panza JA, STICH Trial Investigators: Myocardial viability and survival in ischemic left ventricular dysfunction. $N$ Engl J Med 2011, 364(17):1617-25.

32. Rahimi K, Banning AP, Cheng AS, Pegg TJ, Karamitsos TD, Channon KM, Darby S, Taggart DP, Neubauer S, Selvanayagam JB: Prognostic value of coronary revascularisation-related myocardial injury: A cardiac magnetic resonance imaging study. Heart 2009, 95:1937-1943.

33. Wikstrom G, Blomstrom-Lundqvist C, Andren B, Lonnerholm S, Blomstrom P, Freemantle N, Remp T, Cleland JG: The effects of aetiology on outcome in patients treated with cardiac resynchronization therapy in the care-hf trial. Eur Heart J 2009, 30:782-788.

34. Baer FM, Theissen P, Schneider CA, Voth E, Sechtem U, Schicha H, Erdmann E: Dobutamine magnetic resonance imaging predicts contractile recovery of chronically dysfunctional myocardium after successful revascularization. J Am Coll Cardiol 1998, 31:1040-1048.

35. John AS, Dreyfus GD, Pennell DJ, Images in cardiovascular medicine: Reversible wall thinning in hibernation predicted by cardiovascular magnetic resonance. Circulation 2005, 111:e24-25.

36. Kaandorp TA, Bax JJ, Schuijf JD, Viergever EP, van Der Wall EE, de Roos A, Lamb HJ: Head-to-head comparison between contrast-enhanced magnetic resonance imaging and dobutamine magnetic resonance imaging in men with ischemic cardiomyopathy. Am J Cardiol 2004, 93:1461-1464

37. Senior R, Kaul S, Lahiri A: Myocardial viability on echocardiography predicts long term survival after revascularization in patients with ischaemic congestive heart failure. J Am CollCardiol 1999, 33:1848-54.

38. Chaudhry FA, Tauke JT, Alessandrini RS, Vardi G, Parker MA, Bonow RO: Prognostic implications of myocardial contractile reserve in patients with coronary artery disease and left ventricular dysfunction. J Am Coll Cardiol 1999, 34:730-8.

doi:10.1186/1532-429X-13-53

Cite this article as: Bourantas et al:: Prevalence of scarred and dysfunctional myocardium in patients with heart failure of ischaemic origin: A cardiovascular magnetic resonance study. Journal of Cardiovascular Magnetic Resonance 2011 13:53.

\section{Submit your next manuscript to BioMed Central and take full advantage of:}

- Convenient online submission

- Thorough peer review

- No space constraints or color figure charges

- Immediate publication on acceptance

- Inclusion in PubMed, CAS, Scopus and Google Scholar

- Research which is freely available for redistribution

Submit your manuscript at www.biomedcentral.com/submit
Biomed Central 